\title{
Absorption of Oleic and Palmitic Acids \\ from Emulsions and Micellar Solutions
}

\author{
W. J. Simmonds, T. G. Redgrave, and R. L. S. Willix \\ From the Department of Physiology, The University of Western Australia, \\ Nedlands, Western Australia 6009
}

A в S T R A C T A lipid mixture (monoolein, oleic acid- $1-{ }^{14} \mathrm{C}$, and palmitic acid-9, $10-{ }^{3} \mathrm{H}$ ) was infused intraduodenally at a steady rate for $8 \mathrm{hr}$ in fasted, unanesthetized rats. The same dose of lipid was given together with pure conjugated bile salts either as an emulsion, $2.5 \mathrm{~mm}$ bile salts, or as a micellar solution, $10 \mathrm{~mm}$ bile salts. The emulsion contained very little or no micellar lipid. Thoracic duct lymph was collected and in some experiments bile and pancreatic juice were drained to the exterior. After 4-5 $\mathrm{hr}$ infusion the same steady lymphatic output of radioactive fatty acids was obtained with emulsion as with micellar solution. It was concluded that absorption of fatty acid could proceed efficiently in the virtual absence of micellar solubilization. In rats with biliary plus pancreatic fistulae, labeled triglyceride was absorbed poorly relative to free fatty acids in the same emulsified particles. This suggested that fatty acids were transferred to the absorptive cells in monomolecular solution and not as emulsion particles.

Substitution of a synthetic nonionic detergent for bile salts in lipid mixtures given to rats with biliary and pancreatic fistulae did not affect the lymphatic output of radioactive fatty acids. This indicated that mucosal esterification of labeled free fatty acids was normal in the absence of bile salts. The physical state of the lipid did not affect the pathway of absorption. Finally, comparison of the increased output of esterified fat in the lymph with

Address requests for reprints to Dr. W. J. Simmonds, Department of Physiology, The University of Western Australia, Nedlands, Western Australia 6009.

Received for publication 16 August 1967 and in revised form 27 December 1967. the output of labeled fat suggested that fat absorption did not greatly affect the turnover of endogenous, unlabeled fat. Results were consistent with the view that most of the endogenous lymph fat comes from reabsorbed biliary lipid.

\section{INTRODUCTION}

During digestion and absorption, lipids in the lumen of the intestine form a complex physicochemical system. For example, the free fatty acids may be present in unstable oil droplets, in emulsified particles, perhaps in liquid crystalline aggregates, in mixed micelles, or in monomolecular solution. There is evidence that lipids are absorbed in significant amounts only when in a fine state of dispersion as micelles or by diffusion as single molecules (1). It is possible that a limiting factor in absorption might be the rate of transfer of molecules from the very large aggregates found in oil globules or even in finely emulsified particles to the much smaller micellar aggregates or to monomolecular dispersion (2). While the kinetics of transfer of molecules between the different states of aggregation can be more rigorously studied in vitro, preliminary work in vivo seems desirable. Limiting factors in a closed in vitro system may well be different from those in the open in vivo system in which there is steady removal of absorbed products (3).

This paper reports experiments which compared the absorption in lymph fistula rats of two fatty acids (palmitic and oleic acid) from a mixture of fatty acids and monoglycerides. The same mixture was presented either in micellar solution with bile salts or as a fine emulsion. In the latter 
case the bile salts were below the critical micellar concentration (CMC) in the infusate. In the intestine, mixture with endogenous bile salts might still allow formation of some micellar phase but this was controlled by the use of rats with combined biliary and pancreatic fistulae.

The aims of the experiments were $(a)$ to compare absorption rates for the same fatty acid mixture from micellar solution and from emulsion with virtually no micellar phase; $(b)$ to compare absorption rates with two types of micellar solubilizer, bile salts and Pluronic F68, a nonionic detergent; and $(c)$ by giving increasing concentrations of emulsion to see if there was any lag in absorption attributable to delay in transfer of fatty acid from emulsified particles to micellar or monomolecular dispersion. An important feature of the experimental procedure was the steady infusion of lipid into the intestinal lumen for $8 \mathrm{hr}$ so that absorption rates could be compared during the latter half of the experiment when a fairly steady state of absorption had been reached.

\section{METHODS}

General procedure. Male albino rats of Wistar strain, interbred locally for $10 \mathrm{yr}$ and weighing 200-220 g, were used. Operations were done under ether anaesthesia after fasting the animals overnight. The abdominal thoracic duct was cannulated according to the method of Bollman, Cain, and Grindlay (4) with a polyethylene cannula (I.D. $0.5 \mathrm{~mm}$ ). In some rats the bile and pancreatic juice were drained through an elastic silicone cannula tipped with polythene (I.D. $0.25 \mathrm{~mm}$ ). The fine tip was inserted between the junction of common bile and pancreatic ducts and the duodenal wall. In all rats an elastic silicone tube was passed through a small incision in the stomach into the duodenum and its tip was secured near the entrance of the bile duct.

After operation rats were transferred to restraining cages. Thereafter $\mathrm{NaCl}$ solution, $0.9 \mathrm{~g} / 100 \mathrm{ml}$, containing $\mathrm{KCl}, 30 \mathrm{mg} / 100 \mathrm{ml}$, was infused continuously through the duodenal cannula until the end of the experiment, except when it was replaced by lipid mixtures. The volume infused was always $3 \mathrm{ml} / \mathrm{hr}$. The first infusion of lipid was given $48 \mathrm{hr}$ after operation and, in many animals, a second test was performed on the following day. Hourly lymph samples were collected into heparinized, graduated centrifuge tubes for the hour before lipid infusion and during the $8 \mathrm{hr}$ lipid infusion; then a $4 \mathrm{hr}$ lymph collection followed by an 11-12 hr collection made up the overnight lymph recovery.

The infusate contained monoolein (MO), oleic acid $\left(\mathrm{OA} ; \mathrm{C}_{18: 1}\right)$ and palmitic acid $\left(\mathrm{PA} ; \mathrm{C}_{18: 0}\right)$ in molar ratio $2: 2: 1$, with some exceptions noted later. Stock solutions of lipid, kept at $5^{\circ} \mathrm{C}$ were mixed in the desired pro- portions and tracer amounts of oleic acid- $1-{ }^{14} \mathrm{C}$ and palmitic acid- $9,10-{ }^{3} \mathrm{H}$ were added to give $\mathrm{OA}$ a final specific activity of about $12 \times 10^{3} \mathrm{dpm} / \mu$ mole, and PA about $30 \times$ $10^{3} \mathrm{dpm} / \mu$ mole. On the day of the experiment the required volume of lipid mixture was taken and the solvent was completely evaporated under a stream of nitrogen. Pure bile salts or the nonionic detergent, Pluronic F68, in sodium phosphate buffer, $0.15 \mathrm{~mole} /$ liter in $\mathrm{Na}^{+}, \mathrm{pH}$ $6.3 \pm 0.1$, was mixed with an equal volume of $0.9 \% \mathrm{NaCl}$ solution and added to give the desired final concentrations of detergent and lipid. The phosphate buffer was diluted with saline to avoid diarrhea after prolonged administration into the duodenum (5).

For micellar solutions with bile salts the final concentration of conjugated bile salts was 10 mmoles/liter and with Pluronic F68 the concentration was $70 \mathrm{mg} / \mathrm{ml}$ (about 9 mmoles/liter). The final concentration of lipid mixture was about 7 mmoles/liter. The mixture was stirred with a magnetic chuck under nitrogen at $37^{\circ} \mathrm{C}$ until isotropic and kept at $37-42^{\circ} \mathrm{C}$ until used. The micellar solutions remained transparent for long periods in sealed vessels at $37^{\circ} \mathrm{C}$ and those made with $\mathrm{MO}, \mathrm{OA}$, and $\mathrm{PA}$ in molar ratio 2:2:1 were also stable at room temperature. Ultracentrifugation, $7 \times 10^{7} g$-min at $37^{\circ} \mathrm{C}$, showed that all the labeled fatty acid was in micellar solution.

For emulsions with bile salts the final concentration of bile salts was 2.5 mmoles/liter and with Pluronic F68 the final concentration was $5 \mathrm{mg} / \mathrm{ml}$ (about $0.6 \mathrm{mmole} /$ liter). For most experiments the total lipid concentration was $7 \mathrm{mmoles} / \mathrm{liter}$. The material was insonated with a Branson Sonifier ( $40 \mathrm{w}$ at $20,000 \mathrm{cycle} / \mathrm{sec}$ ) for $5 \mathrm{~min}$ to produce a fine emulsion. This was stable at $37^{\circ} \mathrm{C}$ for several days when made with $\mathrm{MO}, \mathrm{OA}$, and $\mathrm{PA}$ in molar ratio $2: 2: 1$, but was always prepared freshly on the day of the experiment. Samples of infusate taken at the beginning, middle, and end of the infusion period were analysed for radioactivity to verify stability. The analyses agreed within $6 \%$ or less. A sample was taken at the middle of the infusion period for estimation of total saponifiable fatty acid.

Ultracentrifugation, $7 \times 10^{7} \mathrm{~g}$-min at $37^{\circ} \mathrm{C}$, of infusates emulsified with $2.5 \mathrm{~mm}$ bile salts, showed that the concentration of labeled fatty acid in the isotropic phase was approximately $4 \times 10^{-5} \mathrm{~mole} / \mathrm{liter}$ for oleic acid and $2 \times 10^{-5}$ mole/liter for palmitic acid. This would be consistent with monomolecular solution, i.e., absence of a micellar phase.

As a further test, the following experiment was performed: The standard lipid mixture MO-OA-PA, molar ratio $2: 2: 1$, was emulsified by insonation in buffer solution alone, and in buffer plus three different concentrations of bile salts $(1.0,2.5$, and 7.5 mmoles/liter $)$. The emulsion in the absence of bile salts was unstable. The isotropic phase was separated from each emulsion by centrifugation, and to $10 \mathrm{ml}$ of isotropic phase was added 3 $\mathrm{mg}$ azobenzene. The mixture was insonated, $40 \mathrm{w}$ at $20,000 \mathrm{cycle} / \mathrm{sec}$, and the optical density measured with a Beckman DB spectrophotometer at $320 \mathrm{~m} \mu$ against phosphate buffer. The optical densities were $0.025,0.025$, 
0.025 , and 0.70 for isotropic phases with $0,1.0,2.5$, and $7.5 \mathrm{~mm}$ bile salt mixture. The optical density for $10 \mathrm{~mm}$ bile salt solution alone in phosphate buffer against a phosphate buffer blank was 0.05 . Thus the isotropic phase of a lipid mixture in $2.5 \mathrm{~mm}$ bile salts solubilized no more azobenzene than did the isotropic phase from a mixture with $1 \mathrm{~mm}$ bile salt or with none. The amount of azobenzene solubilized was very small compared with the amount solubilized by the isotropic phase from a lipid mixture in $7.5 \mathrm{~mm}$ bile salts in which about $6.5 \mu$ mole of total lipid/ml was micellar. It seemed, therefore, that if there were any micellar phase in the emulsified infusate with bile salt concentration $2.5 \mathrm{mmoles} /$ liter, the amount must be very small. A similar conclusion was reached in experiments on micellar solubilization of radioactive fatty acids, see Results. Although such experiments showed that the CMC for the lipid mixture was close to $2.5 \mathrm{~mm}$ bile salts, so that a lower bile salt concentration might have been preferable for emulsified infusates, it was found that emulsions made with lower bile salt concentrations sometimes became unstable, particularly if lipid mixtures were rich in PA. It seemed preferable to accept the possibility of a trace of micellar phase in order to avoid gross errors which would follow breaking of the emulsion, particularly if this occurred in the infusion tubing.

Materials. Glycerol-1-monooleate (Monoolein) 1 was shown by thin-layer chromatography (TLC) to contain a small amount of diglyceride and free fatty acid. By gasliquid chromatography (GLC) the percentage fatty acid composition was- $\mathrm{C}_{12: 0}, 1 ; \mathrm{C}_{16: 1}, 5 ; \mathrm{C}_{18: 1}, 85 ; \mathrm{C}_{18: 2}, 5$. Oleic acid ${ }^{2}$ was $98.5 \%$ pure and palmitic acid ${ }^{3}$ was $99 \%$ pure by GLC. Radiochemical purity of oleic acid-1- ${ }^{14} \mathrm{C}, 4$ was certified by the suppliers as $95-98 \%$ pure C18:1 of which $5-7 \%$ was elaidic acid. On TLC in a mixture with unlabeled MO, OA, and PA $98 \%$ of the radioactivity was recovered in the free fatty acid band. Palmitic acid-9,10${ }^{3} \mathrm{H},{ }^{4}$ was certified by the suppliers as $96 \%$ pure. On TLC in a mixture with unlabeled $\mathrm{MO}, \mathrm{OA}$, and $\mathrm{PA} 95 \%$ of the radioactivity was recovered in the free fatty acid band. Glyceryl tri(oleate- $\left.1-{ }^{14} \mathrm{C}\right),{ }^{4}$ was certified by the suppliers as $98-99 \%$ pure. The labeled and unlabeled lipids were all used without further purification.

The bile salt mixture consisted of sodium taurocholate (NaTC) and sodium taurodeoxycholate (NaTDC) in molar ratio $4: 1$. The $\mathrm{NaTC}^{2}$ moved as a single spot on TLC and was used as supplied. The NaTDC was synthesized from taurine ${ }^{3}$ and deoxycholic $\operatorname{acid}^{5}$ by the method of Norman, modified by Hofmann (6). The deoxycholate moved as a single spot on TLC. The synthetic NaTDC showed only a trace of free bile salts. The nonionic detergent, Pluronic F68, 6 has been described as a block copolymer of propylene and ethylene

\footnotetext{
1 Calbiochem, Los Angeles, Calif.

2 Koch Light Laboratories, Colnbrook, Bucks, England.

3 Eastman Organic Chemicals, Rochester, N. Y.

4 Radiochemical Centre, Amersham, England.

5 Nutritional Biochemical Corporation, Cleveland, Ohio.

${ }^{6}$ Kindly donated by Wyandotte Chemicals Corp., Wyandotte, Mich.
}

oxides of average molecular weight 8000 (7) and was used as supplied.

Analytical. TLC was carried out on $0.25 \mathrm{~mm}$ layers of Silica Gel $\mathrm{G}^{7}$ on plates reactivated at $110^{\circ} \mathrm{C}$ for $1 \mathrm{hr}$ before use. Up to $250 \mu \mathrm{g}$ of material was applied and developed for $15 \mathrm{~cm}$. For glycerides the solvent system was hexane-ether-acetic acid, 80:20:2 v/v/v. For bile salts ethylacetate-methanol-acetic acid, $70: 20: 10 \mathrm{v} / \mathrm{v} / \mathrm{v}$, was used. GLC of fatty acids was carried out in 4-ft glass columns of $20 \%$ diethylene glycol succinate on Gas-Chrom $\mathrm{CLA}^{8}$ support at $190-200^{\circ} \mathrm{C}$, with argon as carrier gas and a strontium 90 ionization detector. Analyses of standard mixtures (NIH standard mixture) agreed with the specifications with a relative error of less than $6 \%$ for major components and less than $20 \%$ for minor components (less than $10 \%$ of total).

Radioactivity was determined on aliquots of alcoholether extracts of lymph and infusate which had been prepared for analysis of esterified fat (8). The solvent was evaporated and radioactivity was measured in a solution of 2,5-diphenyloxazole, $4 \mathrm{~g} /$ liter, and 1,4-bis[2-(5-phenyloxazolyl) ]benzene, $0.05 \mathrm{~g} /$ liter, in toluene, using a $\mathrm{Nu}$ clear-Chicago counter. Quenching correction was made by the channels ratio method (9) but the degree of quenching was usually less than $10 \%$, so that corrections were small. Samples of infusate were counted at the same time as samples of lymph and recoveries of radioactivity in lymph were expressed as a percentage of ${ }^{14} \mathrm{C}$ and ${ }^{3} \mathrm{H}$ infused. The total radioactivity infused was always about $0.3 \mu \mathrm{c}$ of ${ }^{14} \mathrm{C}$ (OA) and about $0.4 \mu \mathrm{c}$ of ${ }^{3} \mathrm{H}$ (PA).

Total esterified fatty acid in lymph and infusate were measured by the method of Stern and Shapiro (8). Total fatty acid in the infusate was measured, after saponification, by the method of Frazer (10).

Micellar solubilization. Lipid mixtures of the required composition were made up in buffered surfactant solution as described above for infusates. All mixtures were insonated for $5 \mathrm{~min}$ (Branson Sonifier, $40 \mathrm{w}, 20,000$ cycles/sec at $37^{\circ} \mathrm{C} .10 \mathrm{ml}$ was transferred immediately to an ultracentrifuge (Spinco L-2 preparative) without cooling and spun for $7 \times 10^{7} \mathrm{~g}$-min at $37^{\circ} \mathrm{C} .5 \mathrm{ml}$ of the lower isotropic phase was withdrawn without remixing, injected into $15 \mathrm{ml}$ of ethanol-diethyl ether- $n$-hexane, $1: 1: 1$ $\mathrm{v} / \mathrm{v} / \mathrm{v}$, and the lipid extracted by the method of Blankenhorn and Ahrens (11). The solvent was evaporated and radioactivity measured as described above. A 5-ml sample of the original mixture before centrifugation was similarly treated. Control runs showed that less than $2 \%$ of radioactivity was lost in preparation of the emulsion for centrifugation. The volume of supernatant oil and emulsion after centrifugation was negligible and there was no sediment. Fatty acid mass was estimated from radioactivity and the known specific activity.

\section{RESULTS}

Micellar and nonmicellar absorption. Micellar and nonmicellar absorption were compared by in-

\footnotetext{
`E. Merck, Darmstadt, Germany.

8 Applied Science Laboratories Inc., State College, Pa.
} 
fusing the same lipid mixture (MO-OA-PA in molar ratio $2: 2: 1$ ) in about the same concentration, 7 mmoles/liter, varying only the concentration of bile salts or nonionic detergent. The results are summarized in Fig. 1. It can be seen that in all experimental groups a steady infusion of lipid mixture intraduodenally produced within 4-5 $\mathrm{hr}$ a steady rate of transfer of the two labeled fatty acids into lymph.

In rats with intact bile ducts, absorption was the same whether fatty acids were infused in monoolein-bile salt micelles, $10 \mathrm{~mm}$ bile salts, or in monoolein-bile salt emulsion, $2.5 \mathrm{~mm}$ bile salts (compare Fig. 1 A, upper and lower). Micellar solubilization experiments, which are presented later, showed that $2.5 \mathrm{mmoles} /$ liter was close to or below the critical micellar concentration for the bile salt mixture. There was direct evidence that the infusate emulsified with bile salts contained no significant micellar phase, as set out under Mechods. Ultracentrifugation of the emulsified infusate showed that the concentration of labeled fatty acid in the isotropic phase was $3.5 \times 10^{-5} \mathrm{~mole} / \mathrm{liter}$ for oleic acid and $1.7 \times 10^{-5} \mathrm{~mole} /$ liter for palmitic acid, which would be consistent with monomolecular solution.

Although there was virtually no micellar fatty acid in the infused bile salt emulsion, experiments in rats with intact bile ducts did not exclude possible micellar solubilization in the intestinal lumen

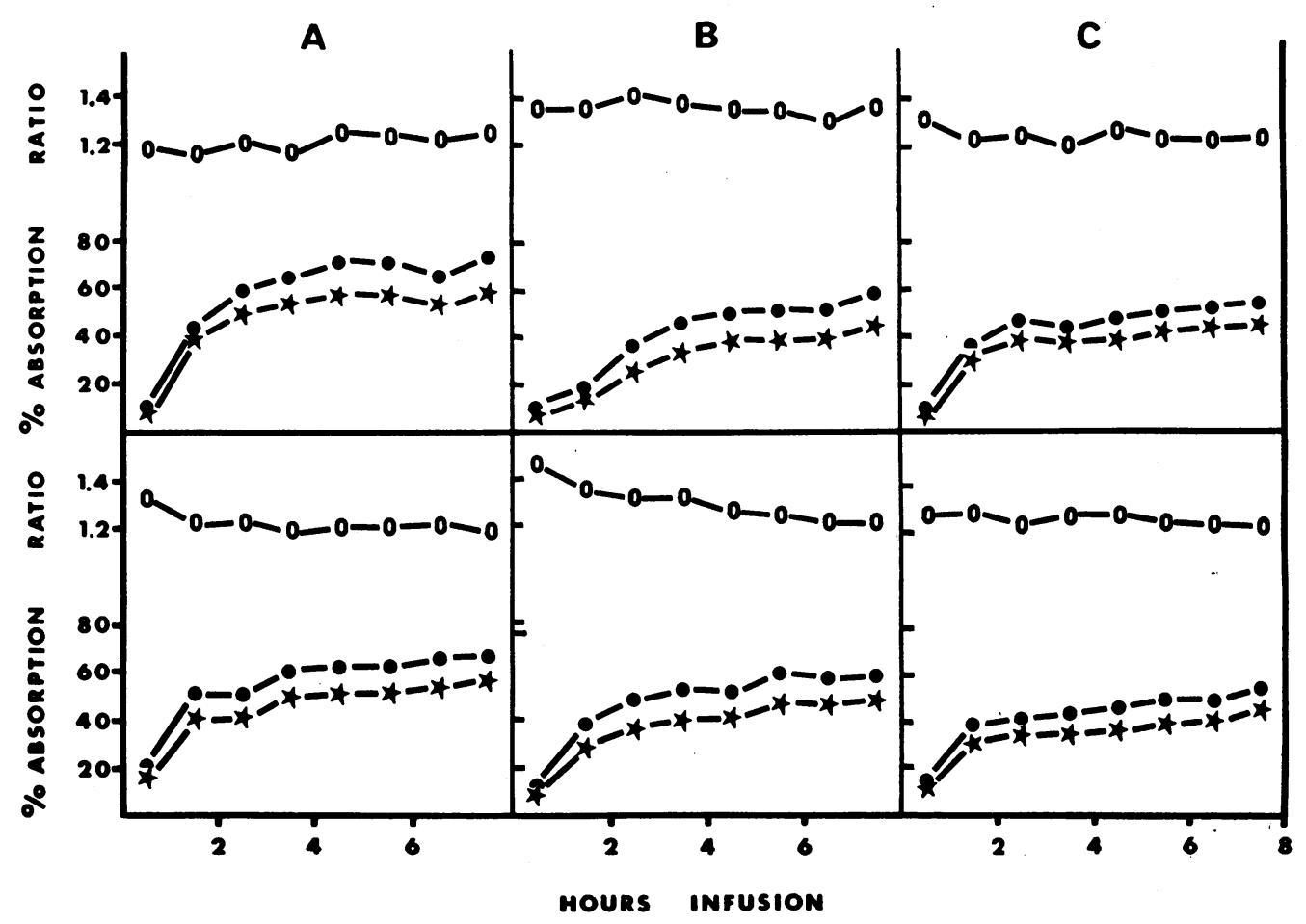

FIGURE 1 Absorption of micellar and emulsified lipid. In all experiments a mixture of monooleinoleic acid- ${ }^{14} \mathrm{C}$-palmitic acid- ${ }^{8} \mathrm{H}$ in molar ratio $2: 2: 1$, concentration 7 mmoles/liter, was infused into the duodenum at approximately $21 \mu$ moles/hr. In the upper graphs the lipid was in micellar solution in a mixture of pure sodium taurocholate-sodium taurodeoxycholate, molar ratio $4: 1,10 \mathrm{mmoles} / \mathrm{liter}$ $(A$ and $B$ ), or in nonionic detergent, Pluronic $\mathrm{F} 68,70 \mathrm{mg} / \mathrm{ml}(C)$. In the lower graphs the lipid was emulsified in the same bile salt mixture, $2.5 \mathrm{mmoles} /$ liter $(A$ and $B)$ or in Pluronic $\mathrm{F} 68,5 \mathrm{mg} / \mathrm{ml}(C)$. The vehicle was phosphate buffer-saline, 0.15 mole/liter in $\mathrm{Na}^{+}, \mathrm{pH} 6.3 \pm 0.1$. In $\mathrm{A}$, upper and lower, the rats had intact bile ducts; in B and $\mathrm{C}$, upper and lower, bile and pancreatic juice were drained to the exterior.

Hourly output of radioactivity in lymph is expressed as per cent of oleic acid- ${ }^{14} \mathrm{C}$, $\bullet-\bullet$, or palmitic acid- ${ }^{3} \mathrm{H}, \star-\star$, infused per hour. The ratio of percentage absorption, oleic acid-palmitic acid, is shown above, $\mathrm{O}-\mathrm{O}$. Each graph is the average of two experiments except $\mathrm{C}$, (lower) which is for a single experiment. 
by endogenous bile salts. This was unlikely in rats with cannulae draining both bile and pancreatic juice (Fig. 1 B). Absorption of fatty acids, whether micellar or emulsified, was somewhat less efficient than in rats with intact bile ducts. This possibly reflects the difficulty of maintaining the doubly depleted animals in optimal condition. However, there was still no difference between absorption of micellar and emulsified fatty acids (compare Fig. 1 B, upper and lower). It should also be noted that fatty acids were absorbed from micellar solution in a nonionic detergent, Pluronic F68, as efficiently as from bile salt micelles (compare Fig. $1 \mathrm{~B}$ and $1 \mathrm{C}$, upper). The number of experiments was small but the results were quite consistent (Table I).

It should perhaps be emphasized that the emulsion made with Pluronic F68 (Fig. 1 C, lower graph) contained a substantial micellar phase. Therefore, comparison of upper and lower graphs in Fig. $1 \mathrm{C}$ gives no information on micellar vs. nonmicellar absorption in the presence of Pluronic F68. Emulsions were unstable when made with low concentrations of Pluronic F68, at or below the CMC for detergent plus the usual mixture of monoolein, oleic acid, and palmitic acid. A detailed comparison with Pluronic F68 was, therefore, not attempted.

In rats with combined bile and pancreatic fistu-

TABLE I

Hourly Lymphatic Output of Radioactive Fatty Acid*

\begin{tabular}{cccccc}
\hline & & \multicolumn{5}{c}{ Lymphatic output } \\
\cline { 3 - 6 } Treatment $\ddagger$ & Infused & Hr. 5 & 6 & 7 & 8 \\
\hline $\mathrm{A}_{\mathrm{m}}$ & $11.9 \pm 0.2$ & $7.2 \pm 0.4$ & $7.3 \pm 0.5$ & $7.1 \pm 0.5$ & $7.1 \pm 0.8$ \\
$\mathrm{~A}_{\mathrm{e}}$ & $12.3 \pm 0.5$ & $7.6 \pm 0.5$ & $8.0 \pm 0.7$ & $8.1 \pm 0.4$ & $8.2 \pm 0.4$ \\
$\mathrm{~B}_{\mathrm{m}}$ & $11.9 \pm 0.04$ & $5.4 \pm 0.5$ & $5.5 \pm 0.3$ & $5.7 \pm 0.1$ & $6.3 \pm 0.2$ \\
$\mathrm{~B}_{\mathrm{e}}$ & $11.9 \pm 0.3$ & $5.7 \pm 0.3$ & $6.6 \pm 0.4$ & $6.4 \pm 0.1$ & $6.6 \pm 02$. \\
$\mathrm{C}_{\mathrm{m}}$ & $12.6 \pm 1.4$ & $6.3 \pm 1.1$ & $7.1 \pm 1.5$ & $6.2 \pm 0.3$ & $6.4 \pm 0.8$ \\
\hline
\end{tabular}

* Calculated, as $\mu$ moles $/ \mathrm{hr}$, from hourly output of ${ }^{14} \mathrm{C}(\mathrm{cpm}) \times$ specific activity $\mathrm{cpm} / \mu$ mole of unesterified oleic acid-14 $\mathrm{C}$ inf used plus hourly output of $\mathbf{\imath}^{\mathbf{2}} \times$ specific activity of unesterified palmitic acid-s $\mathrm{H}$ inf used. $\ddagger A_{m}$, four experiments, intact bile ducts. Micellar infusate in $10 \mathrm{~mm}$ bile salts; monoolein-oleic acid-palmitic acid molar ratio $2: 2: 1$ in two experiments and $2: 1: 2$ in the other two. Results as mean \pm SEM. Ae, four experiments, intact bile ducts. Emulsion in $2.5 \mathrm{~mm}$ bile salts, two experiments with monoolein-oleic acid-palmitic acid molar ratio $2: 2: 1$ and $2: 1: 2$ in the other two. Results as mean \pm SEM. $B_{m}$, two experiments, biliary plus pancreatic fistula. Micellar infusate in 10 mM bile salts; monoolein-oleic acid-palmitic acid molar ratio 2:2:1. Results as mean $t$ half range. $B_{e}$, two experiments same as for $B_{m}$ except that emulsion in $2.5 \mathrm{~mm}$ bile salts was infused. $C_{m}$, two experiments, same as for $B_{m}$ except that Pluronic F68, $70 \mathrm{mg} / \mathrm{ml}$, was used as micellar solubilizer. Total radioactive free fatty acid infused, in $\mu$ moles per hour.
TABLE II

Absorption of Emulsified Triolein in Rats with Pancreatico Biliary Fistulae*

\begin{tabular}{|c|c|c|c|c|}
\hline \multirow[b]{2}{*}{ Rat No. } & \multicolumn{2}{|c|}{ Triolein-14 $\mathrm{C}$} & \multicolumn{2}{|c|}{ Oleic acid- $-14 \mathrm{C}$} \\
\hline & ${ }^{14} \mathrm{C}$ & ${ }^{3} \mathrm{H}$ & ${ }^{14} \mathrm{C}$ & ${ }^{3} \mathrm{H}$ \\
\hline 1 & 5.2 & 32.4 & 55.4 & 47.3 \\
\hline 2 & 24.1 & 42.5 & 63.9 & 53.5 \\
\hline 3 & 17.7 & 30.9 & 41.6 & 35.5 \\
\hline 4 & 9.6 & 30.5 & & \\
\hline
\end{tabular}

* On the left hand side are shown results when the mixture infused was monoolein, glycerol tri(oleate $1{ }^{14} \mathrm{C}$ ), oleic acid (unlabeled), and palmitic acid $9,10^{-3} \mathrm{H}$ in molar ratio for fatty acid chains of $2: 3: 1: 1$, as a fine emulsion in $2.5 \mathrm{~mm}$ bile salts (rat 4) or Pluronic F68, $5 \mathrm{mg} / \mathrm{ml}$ (rats 1,2 , and 3 ). On the right hand side the mixture infused in rats 1 and 3 was monoolein, oleic acid $1{ }^{14} \mathrm{C}$, and palmitic acid-9, $10^{-3} \mathrm{H}$ in molar ratio $2: 2: 1$. In rat 2 the mixture given on the 2 nd day, right-hand side, was the same as on the 1st day except that the free oleic acid was labeled and the triolein was not. Absorption is calculated as per cent of radioactivity infused per hour, averaged for hr 6, 7, and 8 of infusion. The total lipid infused was about $21 \mu$ moles/hr containing about $30 \mu$ moles saponifiable fatty acid in the emulsions containing triolein and $21 \mu$ moles saponifiable fatty acid when no triolein was present.

lae when triolein esterified with oleic acid- $1-{ }^{14} \mathrm{C}$ replaced half the oleic acid in the lipid mixture, the remainder being unlabeled, the absorption of ${ }^{14} \mathrm{C}$ label was greatly decreased but the absorption of palmitic acid- ${ }^{3} \mathrm{H}$ from the same emulsified particles was only slightly decreased (Table II). The oleic acid- $-{ }^{14} \mathrm{C}$ which appeared in the lymph was probably absorbed after hydrolysis of triolein $-{ }^{-14} \mathrm{C}$ by residual lipase. Although rats 1 and 3, Table II, received the same total lipid, in $\mu$ moles, on both days, the molar ratio of free to esterified oleic acid and the total saponifiable fatty acid differed in the two infusates. However, similar results were seen in rat 2 , in which the infusates differed only in the labeling with ${ }^{14} \mathrm{C}$ of triglyceride or free oleic acid, respectively. These experiments suggested that the efficient absorption of emulsified free fatty acid with virtually no micellar phase was due to absorption of fatty acid as a monomolecular solution rather than as emulsified particles.

Varying concentration and composition of lipid mixture. The results presented so far were consistent with absorption of fatty acid by diffusion from monomolecular solution, whether the bulk of the fatty acid was present as micellar aggregates 
or as emulsified droplets. Palmitic acid was transferred to the lymph somewhat more slowly than oleic acid, but here were no differences between micellar and emulsified infusates in the absolute or relative absorption rates of the two fatty acids.

This suggested that transfer of fatty acid from emulsified droplets to molecular dispersion was not a rate limiting step at low concentrations. The effect of increasing the concentration of emulsified lipid was measured in a small series of experiments. Two lipid mixtures were tested with monoolein, oleic acid, and palmitic acid in molar ratios $2: 2: 1$ and $2: 1: 2$, respectively. Since earlier experiments (see Fig. 1) suggested that the effects of combined biliary and pancreatic fistulae might decrease the capacity of lymph fistula rats to handle an absorptive load the biliary and pancreatic ducts were left intact. Some micellar lipid phase might, therefore, have formed in the intestine, although none was present in the infusate. Table III shows the absorption into lymph of labeled fatty acid during the last $3 \mathrm{hr}$ of infusion, when a steady state had been reached. The percentage of infused radioactivity which was absorbed did not decrease with increasing absorptive load. This indicated that the mass of fatty acid absorbed per hour increased pari passu with the load infused. For each lipid mixture absorp-

TABLE III

Steady-State Output of Labeled Fatty Acids in Lymph*

\begin{tabular}{|c|c|c|c|c|c|c|}
\hline \multirow[b]{3}{*}{$\begin{array}{l}\text { Total lipid } \\
\text { concentration }\end{array}$} & \multicolumn{6}{|c|}{ Output as per cent infused } \\
\hline & \multicolumn{3}{|c|}{ High oleic } & \multicolumn{3}{|c|}{ High palmitic } \\
\hline & $\begin{array}{c}\text { Oleic } \\
\text { acid-14 } \mathrm{C}\end{array}$ & $\begin{array}{l}\text { Palmitic } \\
\text { acid- }{ }^{-3} \mathrm{H}\end{array}$ & $\begin{array}{l}\text { Ratio, } \\
{ }^{14} \mathrm{C} /{ }^{3} \mathrm{H}\end{array}$ & $\begin{array}{c}\text { Oleic } \\
\text { acid-14 } \mathrm{C}\end{array}$ & $\begin{array}{l}\text { Palmitic } \\
\text { acid- }{ }^{-3} \mathrm{H}\end{array}$ & $\begin{array}{l}\text { Ratio, } \\
{ }^{14} \mathrm{C} /{ }^{8} \mathrm{H}\end{array}$ \\
\hline \multicolumn{7}{|l|}{ mmoles $/ m l$} \\
\hline \multirow[t]{2}{*}{$7(\mathrm{M}) \ddagger$} & 67 & 56 & 1.20 & 81 & 58 & 1.41 \\
\hline & 71 & 57 & 1.24 & 62 & 37 & 1.68 \\
\hline \multirow[t]{2}{*}{$7(\mathrm{E}) \S$} & 62 & 53 & 1.17 & 77 & 59 & 1.31 \\
\hline & 68 & 56 & 1.22 & 89 & 69 & 1.25 \\
\hline $14(\mathrm{E})$ & 85 & 77 & 1.09 & 79 & 63 & 1.27 \\
\hline $28(\mathrm{E})$ & 87 & 73 & 1.20 & 75 & 55 & 1.38 \\
\hline
\end{tabular}

* Hourly output of oleic acid-1-14C and palmitic acid-9-,10-3 $\mathrm{H}$ as per cent ot radioactivity inf used per hour averaged for $\mathrm{hr} 6,7$, and 8 of infusion. Results of 12 experiments on nine rats are shown. In all experiments on the left-hand side (high oleic) the lipids were monoolein-oleic acidpalmitic acid in molar ratio $2: 2: 1$. On the right-hand side (high palmitic) are results for the ratio $2: 1: 2$, i.e., the proportions of oleic and palmitic acid were reversed. In the lower four experiments on each side the lipids ere emulsified in $2.5 \mathrm{~mm}$ bile salts, sodium taurocholatesodium taurodeoxycholate, $4: 1$ ). In the top two experiments on each side the lipids were micellar in $10 \mathrm{~mm}$ bile salts.

$\ddagger \mathbf{M}$, micellar.

\& $\mathrm{E}$, emulsion. tion of oleic acid relative to palmitic acid over a fourfold range of concentration in emulsion was the same as in a micellar solution.

Endogenous lymph lipid. Infusion of a lipid mixture into the intestine increased the output of esterified fatty acid in the lymph, a steady level being reached within about $5 \mathrm{hr}$. Most of the fatty acid in lymph is esterified. An increase in esterified fatty acid output represented the total increase in output of exogenous plus endogenous fatty acid whereas recovery of infused radioactive fatty acid represented only the exogenous contribution.

In Fig. $2 \mathrm{~A}$ it can be seen that the esterified fatty acid output in lymph increased much more than would have been expected from the recovery of radioactive oleic acid, when micellar solutions rich in bile salts were given to rats with intact bile ducts. That is, there was a substantial increase from endogenous sources. The same high concentration of bile salts had a smaller effect in rats with biliary fistulae, Fig. $2 \mathrm{D}$, than in those with intact bile ducts, Fig. $2 \mathrm{~A}$. The same concentration of administered lipid when emulsified in a low concentration of bile salts had little effect whether there was a biliary fistula, Fig. $2 \mathrm{E}$, or not, Fig. $2 \mathrm{~B}$.

The endogenous esterified fatty acid in lymph was calculated for these experiments, as set out in Table IV. The effect of bile salts in rats with intact bile ducts was statistically significant $(P<$ $0.05 t$ test, $6 d f$, on means A and B). With such small numbers a detailed treatment of the other results is not warranted but they raise some points of interest which are briefly considered in Discussion.

Micellar solubilization. Emulsions were made with lipids mixed in the same proportions as in the absorption experiments, viz. MO-OA-PA in molar ratios $2: 2: 1$ and $2: 1: 2$, but with varying concentrations of each of the two detergents, bile salts and Pluronic F68. The fatty acid composition of the micellar phase separated by high speed centrifugation, $7 \times 10^{7} \mathrm{~g}$-min at $37^{\circ} \mathrm{C}$, is shown in Fig. 3.

In these experiments a constant amount of lipid was used to prepare the emulsion and the concentration of detergent was progressively increased until most of the lipid was solubilized. The objectives were strictly limited. Firstly, we wished to determine approximately the CMC under the 


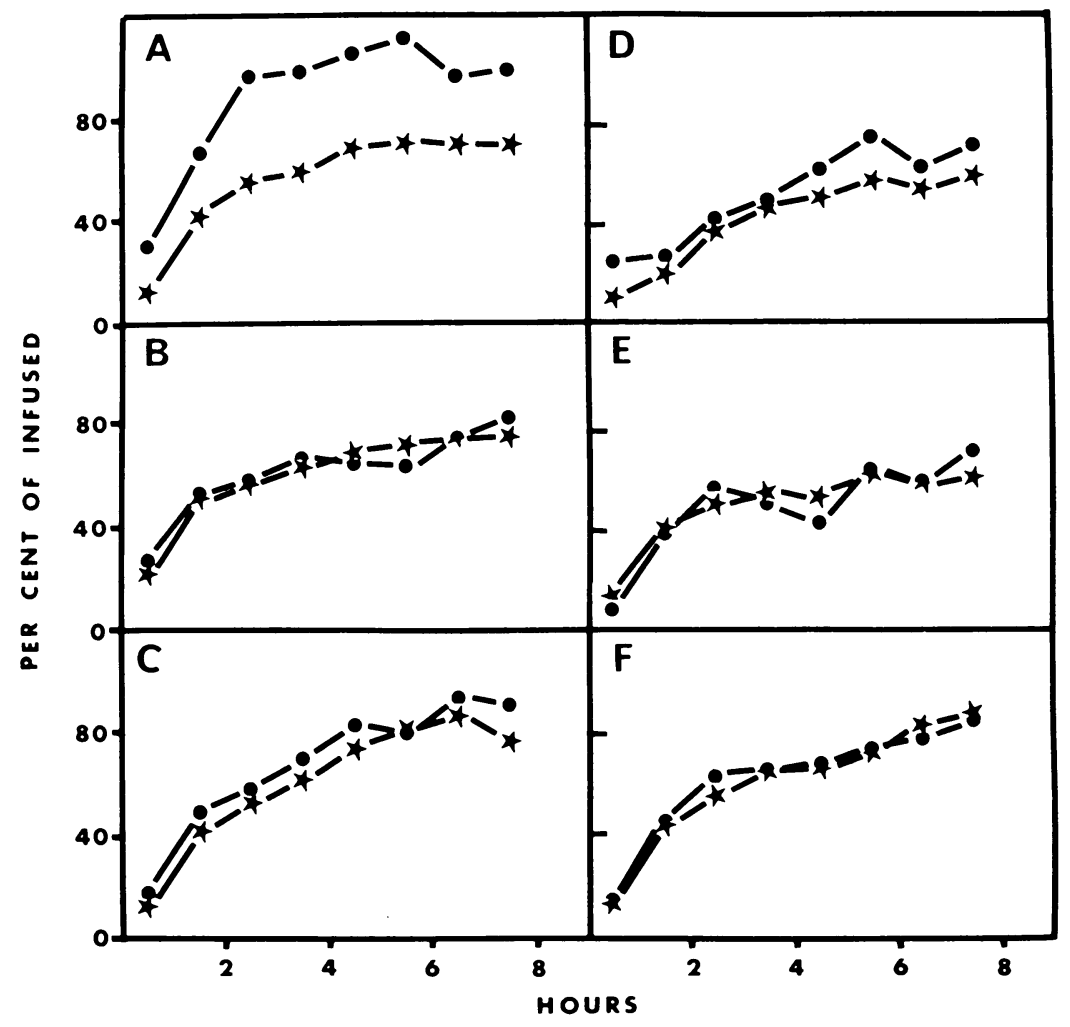

FIGLRE 2 Endogenous fat in lymph. Hourly output in lymph of total esterified fatty acid minus the fasting output in the hour before fat infusion, - $-\bullet$, and output of oleic acid- $-{ }^{14} \mathrm{C}, \star-\star$, are expressed as per cent of amounts, respectively, of saponifiable fatty acid and oleic acid- ${ }^{14} \mathrm{C}$ infused intraduodenally per hour. In all experiments the lipid mixture infused was monoolein-oleic acid- ${ }^{14} \mathrm{C}-$ palmitic acid- ${ }^{3} \mathrm{H}$, molar ratio $2: 2: 1$ in half of each group $A$ to $F$ and $2: 1: 2$ in the remainder of each group, in sodium taurocholate-sodium taurodeoxycholate mixture, 10 mmoles/liter (micellar) or $2.5 \mathrm{mmoles} /$ liter (emulsion), in phosphate-saline, 0.15 moles/liter in $\mathrm{Na}^{+}, \mathrm{pH} 6.3 \pm 0.1$. A, bile ducts intact, micellar lipid $21 \mu$ moles/hr (4) (numbers in parentheses equal number of experiments) ; $\mathrm{B}$, bile ducts intact, emulsion, $21 \mu$ moles/hr (4) ; C, bile ducts intact, emulsion, t2 $\mu$ moles/hr (2); D, bile and pancreatic fistula, micellar lipid, $21 \mu$ moles $/ \mathrm{hr}$ (2) ; E, bile and pancreatic fistula, emulsion, $21 \mu$ moles $/ \mathrm{hr}(2)$; and $\mathrm{F}$, bile ducts intact, emulsion $84 \mu$ moles/hr (2).

conditions used for preparing emulsions. The solubilization curves indicated a CMIC a little above $2.5 \mathrm{mmoles} / \mathrm{liter}$ for the bile salt mixture ( $\mathrm{NaTC}$ NaTDC $4: 1$ ) and about 0.1 mmole/liter for the nonionic detergent, Pluronic F68. Fig. 3 does not show the rery low concentrations of radioactive free fatty acid in the isotropic phase with bile salt, 2.5 mmoles/liter and below, nor could these concentrations be estimated very accurately. In three mixtures with $1.0,1.5$, and $2.0 \mathrm{~m} \times \mathrm{r}$ bile salts the concentrations in the isotropic phase of oleic acid${ }^{14} \mathrm{C}$ were approximately $4 \times 10^{-6}, 1 \times 10^{-5}$, and
$5 \times 10^{-6}$ mole/liter, respectively. In $2.5 \mathrm{~mm}$ bile salts the concentration of oleic acid- ${ }^{14} \mathrm{C}$ was $4 \times$ $10^{-5} \mathrm{~mole} / \mathrm{liter}$ and that of palmitic acid was $2 \times$ $10^{-5} \mathrm{~mole} / \mathrm{liter}$. More detailed work would be needed to establish the significance of this difference from free fatty acid concentrations with lower concentrations of bile salts but the values at 2.5 m.r bile salts were still within the likely range for monomolecular solution of free fatty acid. For reasons mentioned under Methods $2.5 \mathrm{~mm}$ bile salts was used for lipid emulsions rather than concentrations well below the CMC. 
TABLE IV

Hourly Output of Endogenous Lipid in Lymph

\begin{tabular}{crrrrrr}
\hline & & \multicolumn{5}{c}{ Increase during infusion 8} \\
\cline { 3 - 6 } Groups & Preinfusion $\neq$ & \multicolumn{1}{c}{ Hr. .5 } & \multicolumn{1}{c}{6} & \multicolumn{1}{c}{7} & \multicolumn{1}{c}{ Total } \\
\hline A & $17.5 \pm 0.6$ & $8.3 \pm 2.2$ & $8.9 \pm 3.3$ & $6.6 \pm 1.8$ & $7.3 \pm 2.3$ & $31.1 \pm 8.9$ \\
B & $18.8 \pm 1.7$ & $-0.3 \pm 1.4$ & $0.1 \pm 1.6$ & $0.8 \pm 0.4$ & $2.4 \pm 2.2$ & $3.2 \pm 4.8$ \\
C & $20.4 \pm 1.2$ & $4.9 \pm 1.4$ & $1.5 \pm 0.6$ & $4.0 \pm 0.8$ & $6.4 \pm 0.8$ & $16.7 \pm 3.5$ \\
D & $7.5 \pm 2.0$ & $2.6 \pm 3.0$ & $5.0 \pm 0.4$ & $2.4 \pm 0.5$ & $2.9 \pm 2.0$ & $12.8 \pm 4.2$ \\
E & $4.0 \pm 2.4$ & $-1.7 \pm 0.1$ & $0.9 \pm 2.0$ & $-0.3 \pm 1.7$ & $1.5 \pm 0.6$ & $21 \pm 4.7$ \\
F & $14.9 \pm 1.4$ & $5.1 \pm 1.3$ & $5.8 \pm 9.3$ & $1.5 \pm 2.7$ & $2.2 \pm 0.9$ & $14.0 \pm 6.8$ \\
\hline
\end{tabular}

* Groups as in Fig. 2.

$\ddagger$ Fasting output of esterified fatty acid in $\mu$ moles per hour for 1-2 hr before intraduodenal infusion of lipid.

$\S$ The preinfusion output of esterified fatty acid (endogenous) was subtracted from the total esterified fatty acid output during the specified hour of infusion, to give the increase in esterified fatty acid atributable to infusion. The portion of the increase due to exogenous fatty acid was calculated from recovery of palmitic acid- $\mathrm{H}^{3} \times$ specific activity of infushed palmitic acid plus recovery of oleic acid- ${ }^{14} \mathrm{C} \times$ specific activity of infused oleic acid, including monoolein. This assumed the same efficiency of absorption of free, labeled oleic acid and unlabeled monoolein. The endogenous contribution was obtained by subtracting the calculated increase of exogenous origin from the total increase in esterified fatty acid attributable to infusion. Mean \pm SEM for $\mathrm{A}$ and $\mathrm{B}$ (four experiments in each); mean \pm half range for $\mathrm{C}$ through $\mathrm{F}$ (two experiments in each).

Secondly, we wished to see if the molar ratio of the two labeled fatty acids remained the same in the micellar phase as in the total lipid mixture

while the proportion of micellar to emulsified lipid varied widely. This proved to be the case.

Finally, the nonionic detergent was a more effi-

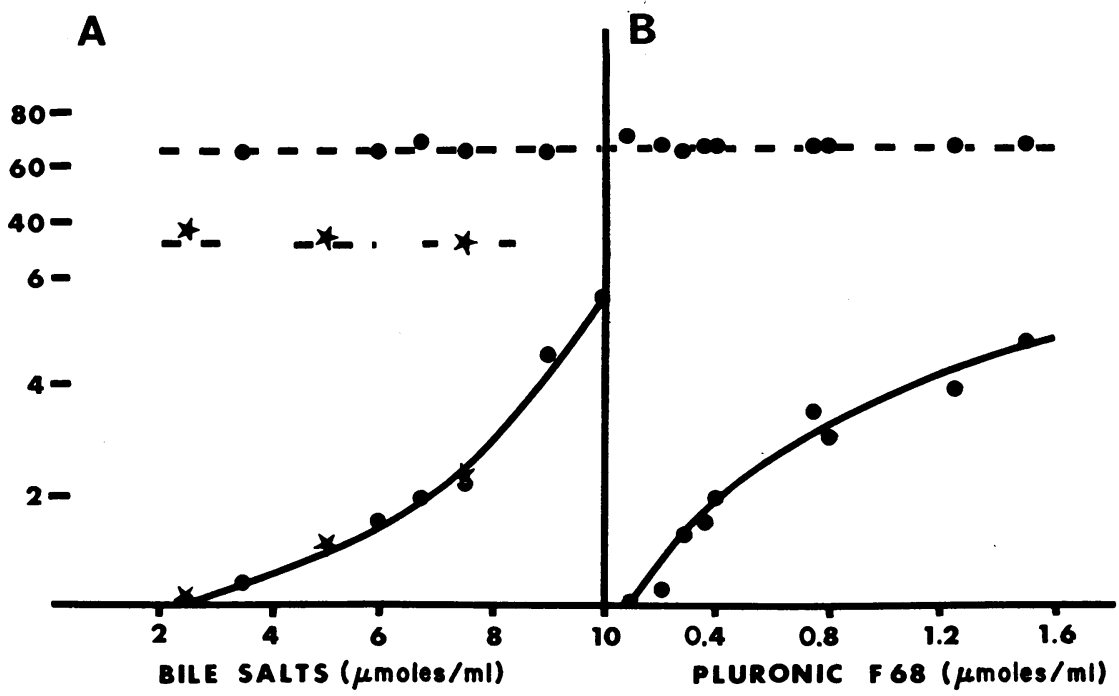

FIgURE 3 Micellar solubilization, in vitro. Total fatty acid concentration, mmoles/ liter, in micellar solution calculated from the specific activity of oleic acid- ${ }^{14} \mathrm{C}$ and palmitic acid- ${ }^{3} \mathrm{H}$ and the radioactivity in the isotropic infranatant fluid after centrifugation, $7 \times 10^{7} \mathrm{~g}$-min at $37^{\circ} \mathrm{C}$. The total concentration of lipid was always $10 \mathrm{mmoles} /$ liter, of which free fatty acids constituted $6 \mathrm{mmoles} /$ liter in phosphate-saline, 0.15 mole/liter in $\mathrm{Na}^{+}, \mathrm{pH} 6.3 \pm 0.1$. ๑, monoolein-oleic acid- ${ }^{14} \mathrm{C}-$ palmitic acid- ${ }^{8} \mathrm{H}$, molar ratio $2: 2: 1$ and $\star$, in molar ratio $2: 1: 2$, respectively. At the top it can be seen that oleic acid always constituted the same percentage of total labeled fatty acids in the micellar phase, - and $\star$, as in the starting material, dashed line, which formed the final mixture of micellar and emulsion phases. 
cient solubilizer on a molar basis for monooleinfatty acid mixture than were the mixed bile salts. This seeming advantage might only hold for a limited range of conditions; for example, it will be noted that the shapes of the solubilization curves are different (Fig. $3 \mathrm{~A}$ and $\mathrm{B}$ ). A more detailed study of the mixed Pluronic F68 micelle should prove interesting.

\section{DISCUSSION}

If a micellar phase was present in the bile salt emulsion the amount must have been extremely small, yet fatty acids were absorbed as effectively as from micellar solution. It is important to exclude the possibility that a significant micellar phase was formed from the emulsion in the intestinal lumen. In rats with intact bile ducts this might have occurred by addition of endogenous bile salts or other amphipaths to the emulsion; but results were the same in rats with combined biliary and pancreatic fistulae. Even in such animals it could be argued that absorption of fluid from the lumen could have raised the concentration of administered bile salts above the CMC. However, no micellar fatty acid was found by centrifugation of undiluted intestinal contents taken after infusion of bile salt emulsion for $3.5 \mathrm{hr}$. The rat is an unsatisfactory animal for detailed physicochemical study of intestinal contents but it seems reasonable to conclude that if a micellar phase was present either in the lumen or in the bile salt emulsions which were administered the amount of micellar lipid must have been very small.

Absorption of nonmicellar lipid from emulsions might proceed by uptake of particles or by diffusion from monomolecular solution. The latter seems much more likely. As Table II shows, palmitic acid- ${ }^{3} \mathrm{H}$ was absorbed much more rapidly than triolein $-{ }^{14} \mathrm{C}$ from the same emulsified particles, whereas emulsified free oleic acid- ${ }^{14} \mathrm{C}$ was absorbed somewhat more rapidly than palmitic acid- ${ }^{3} \mathrm{H}$. The ${ }^{14} \mathrm{C}$ label which did appear in the lymph from triolein $-{ }^{14} \mathrm{C}$ emulsions could be explained by residual lipolytic activity in the lumen liberating labeled oleic acid (12).

Absorption from a micellar solution was no faster than nonmicellar absorption for the same low dose of fatty acid, but it is possible that nonmicellar absorption might be rate limited at a higher dosage. For example, micellar aggregates might serve as a reservoir of fatty acid to prevent desaturation of monomolecular solution when fatty acid molecules were being taken up rapidly into the epithelial cell membrane from the adjacent layer, a few molecules thick, of unstirred luminal fluid $(13,14)$. Further work on this possibility is needed. In a small number of experiments no evidence of rate limitation was found when an increasing dosage of emulsion free of micellar phase was administered to rats with intact bile ducts (Table II).

Morgan (15) found that in bile fistula rats, oleic acid finely emulsified with Pluronic F68 was absorbed at a rate comparable with the normal dietary load. In his experiments the concentration of Pluronic F68, $0.6 \mathrm{mg} / \mathrm{ml}$, was close to the CMC determined for a monoolein, fatty acid mixture in the present experiments. However, lecithin was also present in Morgan's emulsions so that some lysolecithin might have been formed in the lumen as an additional micellar solubilizer.

Calculations suggest that diffusion could account for transfer of the normal dietary load of fat, as fatty acid, from lumen to intestinal epithelium $(14,16)$. Although absorption of dietary triglyceride is known to be defective when micellar solubilization is defective, the concurrent defects in emulsification and lipolysis have not been ruled out as rate limiting factors; equilibration between large globules and single lipid molecules in solution might be very slow. The emulsion prepared by insonation in the present experiments may have been finer than that attained normally during digestion of lipid. The influence of the interfacial area of emulsion on exchange rates with monomolecular solution has yet to be determined. The present experiments, however, suggest quite strongly that a minimal or absent micellar phase need not interfere with transfer of lipid from intestinal lumen to lymph.

Micellar solubilization of itself may confer no great advantage in absorption of lipid molecules such as ionized fatty acids which have a definite though low solubility as single molecules in aqueous solution. Yet the same may not be true for virtually insoluble lipid such as cholesterol. Cholesterol absorption is negligible in the absence of bile salts (17) and it may be that uptake after collision of micelles with the cell membrane is the only truly significant mode of transfer of highly 
insoluble lipid from lumen to cell. Experiments similar to those described for fatty acid will next be undertaken with cholesterol. While the nature of the micellar solubilizer seems unimportant for fatty acid absorption (Fig. 1) it will be of interest to see if this is also true for cholesterol absorption.

The results with micellar solution in nonionic detergent support other evidence (15) that bile salts are not necessary for efficient reesterification during absorption. Moreover, since the lipid was micellar the suggestion of Saunders and Dawson (18) that fine emulsion promotes pinocytosis which in turn promotes lymphatic transport is not applicable to these experiments.

Whether micellar or nonmicellar, oleic acid was absorbed somewhat more rapidly relative to the infused load than was palmitic acid. Evidence from the present experiments does not suggest that the difference can be attributed to differences in micellar solubility or in partition between micellar phase and emulsion particles. There is very little data on solubility of fatty acids in monomolecular dispersion under the conditions found in the intestinal lumen and an attempt is being made at in vitro measurements. In vivo, the steady-state infusion method offers an opportunity to discriminate between intraluminal and intracellular factors determining differences in absorption of different lipids. It will be necessary to use animals larger than rats to allow serial sampling of intestinal contents for physicochemical measurements.

Endogenous fatty acid in the lymph. Nearly all the fatty acid in lymph is esterified, whether of dietary or nondietary (endogenous) origin. Evidence is accumulating that a major part of the endogenous fatty acid in fasting rats is absorbed into the lymph from biliary phospholipids in the intestinal lumen $(19,20)$. After fat feeding there is a substantial dilution of labeled dietary fat by unlabeled endogenous fat $(21,22)$. However, in concluding that absorption of dietary fat promotes the turnover of endogenous fatty acid the basal, fasting contribution needs to be taken into account. In groups of thoracic duct fistula rats studied in this department during the past $10 \mathrm{yr}$, the average fasting output of ester fat has always been close to $20 \mu \mathrm{Eq} / \mathrm{hr}$, i.e., about $120-150 \mathrm{mg}$ of endogenous fatty acid per day. This is similar to the total amount of unlabeled fatty acid found by Karmen, Whyte, and Goodman (21) in 24-hr collections of lymph after fatty meals. They measured basal output but the value, $5-20 \mathrm{mg} / 24 \mathrm{hr}$, was much lower than usually reported.

In the present work the amount of unlabeled fatty acid in lymph increased less with increasing absorptive load of labeled fatty acid (Figs. 2 B, C, and $F$ ) than with a small dose of lipid solubilized in a high concentration of bile salts (Fig. $2 \mathrm{~A}$ ). The latter effect was probably due to increased biliary secretion of phospholipid into the intestinal lumen, since the same lipid-bile salt mixture had a smaller effect on endogenous fat in rats with bile fistulae (Fig. 2 D).

The present experiments were not primarily designed to see whether absorption of dietary fat increased the endogenous output in lymph. It would be premature to stress the apparent lack of effect in these few experiments compared with the increased endogenous contribution inferred by other workers $(21,22)$. The weaknesses of the present experiments were the use of unlabeled monoolein in the lipid mixture and the lack of data on the distribution of fatty acid by radioactivity and by mass (gas-liquid chromatography) in the lymph (21). However, there are two useful features of the present approach. The analysis of serial lymph samples allows the basal, fasting endogenous contribution to be compared with any changes during fat feeding and shows the timing of any increase in the endogenous component. The steady infusion of test lipid mixture allows the dilution of exogenous lipid to be measured under conditions of steady transfer of absorbed fat from intestinal epithelium into lymph. Steadystate experiments with full lipid analysis in normal and bile fistula rats should help to settle the issue.

\section{ACKNOWLEDGMENTS}

We wish to thank Miss Morag Long (English Speaking Union Vacation Scholar) and Mr. W. J. Strickland (National Heart Foundation of Australia Vacation Scholar) who participated in aspects of the work and Miss V. Orton who gave valuable technical assistance throughout.

The nonionic detergent, Pluronic F68, was a gift from Wyandotte Chemical Co., Wyandotte, Mich.

This work was supported by grants from the Australian Research Grants Committee, The National Health and Medical Research Council of Australia, and the Medical Research Grants Committee of the University of Western Australia. Dr. Redgrave is a Life Insurance Medical Re- 
search Fund of Australia and New Zealand fellow. Dr. Willix is an Australian Research Grants Committee postdoctoral fellow.

\section{REFERENCES}

1. Senior, J. R. 1964. Intestinal absorption of fats. J. Lipid Res. 5: 495.

2. Hofmann, A. F. 1966. A physicochemical approach to the intraluminal phase of fat absorption. Gastroenterology. 50: 56.

3. Feldman, E. B., and B. Borgström. 1966. Absorption of sterols by intestinal slices in vitro. Biochim. Biophys. Acta. 125: 148.

4. Bollman, J. L., J. C. Cain, and J. H. Grindlay. 1948. Techniques for the collection of lymph from the liver, small intestine or thoracic duct of the rat. J. Lab. Clin. Med. 33: 1349.

5. Redgrave, T. G. 1967. The absorption of micellar lipid into the lymph of unanesthetized rats. Quart. J. Exptl. Physiol. 52: 130.

6. Hofmann, A. F. 1963. The preparation of chenodeoxycholic acid and its glycine and taurine conjugates. Acta Chem. Scand. 17: 173.

7. Schmolka, I. R., and A. J. Raymond. 1965. Micelle formation of polyoxyethylene-polyoxypropylene surfactants. J. Am. Oil Chemists' Soc. 42: 1088.

8. Stern, I., and B. Shapiro. 1953, Rapid and simple method for determination of esterified fatty acids and for total fatty acids in blood. J. Clin. Path. 6: 158.

9. Hendler, R. W. 1964. Procedure for simultaneous assay of two $\beta$-emitting isotopes with the liquid scintillation counting technique. Anal. Biochem. 7: 110.

10. Frazer, A. C. 1960. Daily fatty acid excretion (Broadsheet No. 28). Association of Clinical Pathologists. Royal Berkshire Hospital, Reading, United Kingdom.

11. Blankenhorn, D. H., and E. H. Ahrens, Jr. 1955. Extraction, isolation and identification of hydrolytic products of triglyceride digestion in man. J. Biol. Chem. 212: 69.

12. Masarei, J., and W. J. Simmonds. 1966. Fat absorption in pancreatic deficiency in rats. Gut. 7: 114.

13. Dean, R. B., and J. R. Vinograd. 1942. Diffusion of solubilized dyes in water and through membranes. J. Phys. Chem. 46: 1091.

14. Hogben, C. A. M. 1966. Fat absorption: a transport problem. Gastroenterology. 50: 51.

15. Morgan, R. G. H. 1964. The effect of bile salts on the lymphatic absorption by the unanesthetized rat of intraduodenally infused lipids. Quart. J. Exptl. Physiol. 49: 457.

16. Davson, H., and J. F. Danielli. 1952. The permeability of natural membranes. Cambridge University Press, London. 2nd edition. 123.

17. Borja, C. R., G. V. Vahouny, and C. R. Treadwell. 1964. Role of bile and pancreatic juice in cholesterol absorption and esterification. Am. J. Physiol. 206: 223.

18. Saunders, D. R., and A. M. Dawson. 1963. The absorption of oleic acid in the bile fistula rat. Gut. 4: 254.

19. Baxter, J. H. 1966. Origin and characteristics of endogenous lipid in thoracic duct lymph in rat. J. Lipid Res. $7: 158$.

20. Shrivastava, B. K., T. G. Redgrave, and W. J. Simmonds. 1967. The source of endogenous lipid in the thoracic duct lymph of fasting rats. Quart. J. Exptl. Physiol. 52: 305.

21. Karmen, A., M. Whyte, and D. S. Goodman. 1963. Fatty acid esterification and chylomicron formation during fat absorption. I. Triglycerides and cholesterol esters. J. Lipid Res. 4: 312.

22. Savary, P., and M. J. Constantin. 1966. Sur la résorption intestinale des chaines éruciques et leur incorporation dans les chylomicrons lymphatiques du rat. Biochim. Biophys. Acta. 125: 118. 